\title{
Lifestyle Factors and Bowel Preparation for Screening Colonoscopy
}

\author{
Jong Hee Hyun ${ }^{1}$, Sang Jin Kim ${ }^{1}$, Jung Hun Park ${ }^{1}$, Gyung Ah Wie ${ }^{2}$, Jeong-seon Kim², Kyung Su Han ${ }^{1}$, \\ Byung Chang Kim ${ }^{1}$, Chang Won Hong ${ }^{1}$, Dae Kyung Sohn ${ }^{1}$ \\ ${ }^{1}$ Center for Colorectal Cancer, Research Institute and Hospital, National Cancer Center, Goyang; ${ }^{2}$ Department of Clinical Nutrition, Research \\ Institute and Hospital, National Cancer Center, Goyang; ${ }^{3}$ Division of Cancer Epidemiology and Prevention, Research Institute, National \\ Cancer Center, Goyang, Korea
}

Purpose: The quality of bowel preparation is a major determinant of the quality of colonoscopy. This study evaluated lifestyle factors, including usual dietary style, associated with bowel preparation.

Methods: This retrospective study evaluated 1,079 consecutive subjects who underwent complete colonoscopy from December 2012 to April 2014 at National Cancer Center of Korea. Questionnaires on bowel preparation were completed by the subjects, with the quality of bowel preparation categorized as optimal (excellent or good) or suboptimal (fair, poor or inadequate). Lifestyle factors associated with bowel preparation were analyzed.

Results: The 1,079 subjects included 680 male (63.0\%) and 399 female patietns (37.0\%), with a mean age of $49.6 \pm 8.32$ years. Bowel preparation was categorized as optimal in 657 subjects (60.9\%) and as suboptimal in $422(39.1 \%)$. Univariate analyses showed no differences between groups in lifestyle factors, such as regular exercise, alcohol intake, smoking, and dietary factor. Body mass index $(\mathrm{BMI})>25 \mathrm{~kg} / \mathrm{m}^{2}$ was the only factor associated with suboptimal bowel preparation on both the univariate $(\mathrm{P}=0.007)$ and the multivariate (odds ratio, 1.437; 95\% confidence interval, $1.104-1.871 ; \mathrm{P}=0.007$ ) analyses.

Conclusion: Most lifestyle factors, including dietary patterns, exercise, alcohol intake and smoking, were not associated with suboptimal bowel preparation in Koreans. However, BMI $>25 \mathrm{~kg} / \mathrm{m}^{2}$ was independently associated with suboptimal bowel preparation. More intense preparation regimens before colonoscopy can be helpful in subjects with BMI $>25 \mathrm{~kg} / \mathrm{m}^{2}$.

Keywords: Colonoscopy; Quality; Dietary supplements; Life style

\section{INTRODUCTION}

Colorectal cancer (CRC) is the third most common cancer and the fourth leading cause of cancer-related deaths in Korea [1]. Colonoscopy and the associated removal of precancerous lesions have been shown to reduce CRC-associated mortality rates [2].

Received: January 10,2017 - Accepted: March 13, 2018

Correspondence to: Dae Kyung Sohn, M.D.

Center for Colorectal Cancer, National Cancer Center, 323 Ilsan-ro,

Ilsandong-gu, Goyang 10408, Korea

Tel: +82-31-920-1636, Fax: +82-31-920-0149

E-mail: gsgabal@ncc.re.kr

ORCID code: https://orcid.org/0000-0003-3296-6646

(C) 2018 The Korean Society of Coloproctology

This is an open-access article distributed under the terms of the Creative Commons Attribution NonCommercial License (http://creativecommons.org/licenses/by-nc/4.0) which permits unrestricted noncommercial use, distribution, and reproduction in any medium, provided the original work is properly cited.
Despite its invasiveness, colonoscopy is considered the standard diagnostic method for CRC and other colorectal diseases, as well as for the removal of precancerous polyps. The efficacy of colonoscopy depends on several factors. The presence of adenomatous polyps affects the risk of CRC after screening colonoscopy [3]. Detection of adenomas, however, depends on the ability to visualize the colonic mucosa, emphasizing the importance of bowel preparation [4-6]. However, bowel preparation at the time of colonoscopy is found to be suboptimal in about $20 \%$ of subjects [5].

Suboptimal bowel preparation has been associated with longer intubation time, decreased cecal intubation rate, a higher rate of missed lesions, increased patient discomfort and a higher risk of complications [7]. Factors associated with suboptimal bowel preparation have been found to include in inpatient status, constipation, use of tricyclic antidepressants, later colonoscopy starting 
time, male sex, and low socioeconomic status [8]. Other factors associated with suboptimal bowel preparation include increased body mass index (BMI) [9] and a low residue diet [10, 11]. The normal Korean diet includes high amounts of fiber and sodium. However, dietary patterns in Korea have become more westernized with industrialization. This study was designed to evaluate the relationship between lifestyle factors, including dietary patterns, and quality of bowel preparation for screening colonoscopy in Korean subjects.

\section{METHODS}

\section{Subjects and data collection}

Individuals enrolled in this study underwent self-motivated comprehensive cancer screening, including colonoscopy at the Center for Cancer Prevention and Detection of the National Cancer Center (NCC, Goyang, Korea) between December 2012 and April 2014. This study was approved by the Institutional Review Board of the NCC (NCC2014-0218). All participating subjects provided signed informed consent before enrollment. Of the 6,436 consecutive subjects who had undergone screening colonoscopy at our institution, 5,344 did not respond to the questionnaires and dietary surveys. Fifteen subjects could not undergo complete colonoscopy, and one underwent sigmoidoscopy with Yal enema (Fig. 1).

Subjects who had undergone screening colonoscopy were prospectively given questionnaires on environmental, lifestyle and host factors associated with the risk of cancer. Questionnaires were mailed to the subjects one week before colonoscopy. Questionnaires included a 3-day food record (1 weekend day and 2-week-days) and questions on family history, surgical or medical history, lifestyle, and education level. The questionnaires were re- turned to the hospital at the time of colonoscopy. During the scheduled visit, subjects' food records were reviewed by trained nutritionists who used aids such as food models to improve reporting accuracy. Daily energy and macro- and micronutrient intakes were calculated using the Korean Nutrition Society's nutrient database (Can-Pro 3.0, The Korean Nutrition Society, Seoul, Korea) [12]. Nutrient density was calculated by standardizing nutrient intake per 1,000 kcal based on everyone's intake. Personal data (age, sex, alcohol consumption, smoking status, personal medical history, and medication history) were collected prior to colonoscopy. Smoking status was classified as current smoker (daily or occasionally), former smoker (quit at least 1 year before), or nonsmoker (lifetime abstainer). Alcohol consumption status was similarly classified. Weight and height measurements were automated (InBody, Biospace Co., Ltd, Seoul, Korea). BMI was calculated as weight in $\mathrm{kg}$ divided by height in $\mathrm{m}^{2}$ and categorized as normal or abnormal, as described previously and according to World Health Organization expert consultation [13].

Before colonoscopy, all subjects were advised on proper methods of bowel preparation, including (1) a low fiber diet for the 72 hours before colonoscopy, (2) a liquid diet on the day before colonoscopy, (3) 2 tablets of 5-mg bisacodyl at $7 \mathrm{PM}$ on the day before colonoscopy, (4) $2 \mathrm{~L}$ of polyethylene glycol plus ascorbic acid, one liter at 6 and the other at 9 PM on the day before colonoscopy. All subjects underwent colonoscopy during the morning using video colonoscopes (Olympus CF-Q240, CF-Q260 or CF-H260, Olympus, Tokyo, Japan).

The adequacy of bowel preparation was assessed by the endoscopists on withdrawal of the colonoscope, by using the Aronchick score as excellent, good, fair or poor [14]. Colonoscopy findings included the presence of polyps, their numbers and sizes, Paris

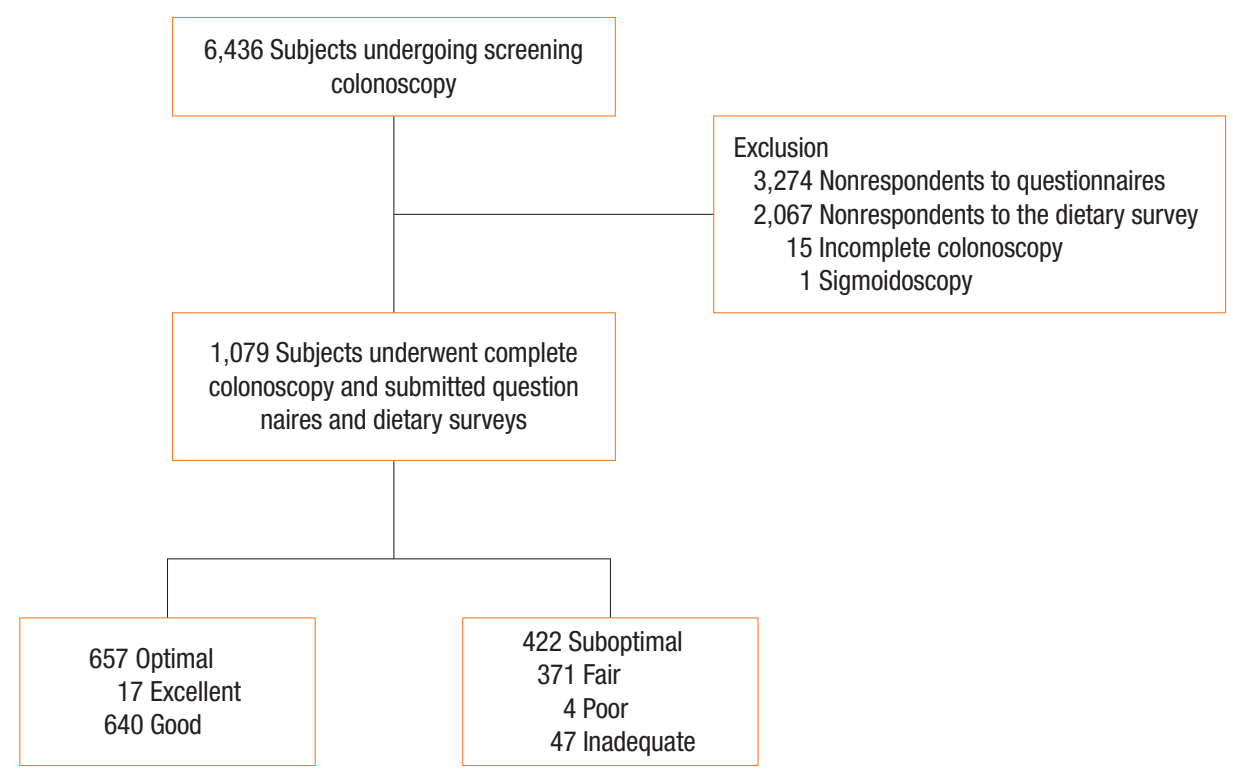

Fig. 1. Flow chart of study. 
classification and methods of polypectomy. Subjects were categorized into 2 group, those with optimal (excellent or good based on the Aronchick score) and suboptimal (fair, poor, or inadequate) bowel preparation.

\section{Statistical analyses}

The study was designed to assess the association between lifestyle factors and bowel preparation. The characteristics of subjects with optimal and suboptimal bowel preparation were compared using Student $\mathrm{t}$-tests for continuous variables and chi-square tests for categorical variables. Daily nutrition and food intake were categorized by quartiles. Regression models were used to assess associations of daily nutrition with food intake and bowel preparation quality. Odds ratios (ORs) and 95\% confidence intervals (CI) were estimated using logistic regression, both in the crude model and in the multivariate model. The multivariate model was adjusted for age, sex, smoking status, and alcohol consumption. Tests for trends were derived from logistic regression with a single term representing the medians of each quartile. A 2-sided P-value less than 0.05 was regarded as statistically significant. All statisti$\mathrm{cal}$ analyses were performed using SAS 9.3 (SAS Institute Inc., Cary, NC, USA) and SPSS ver. 14.0 (SPSS Inc., Chicago, IL, USA).

\section{RESULTS}

A total of 1,079 subjects underwent complete colonoscopy and completed questionnaires and dietary surveys. These 1,079 subjects included 680 male (63.0\%) and 399 female patients (37.0\%), with a mean age $49.6 \pm 8.3$ years. Bowel preparation was categorized as optimal for 657 subjects (60.9\%) and as suboptimal for 422 subjects (39.1\%). Preparation quality was characterized as excellent for 17 (1.6\%), good for 640 (59.3\%), fair for $371(34.4 \%)$, poor for four (0.4\%) and inadequate for 47 subjects (4.3\%) (Fig. 1). The 1,079 included subjects had a mean BMI of $24.1 \pm 2.9$ and a mean waist-to-hip ratio of $0.89 \pm 0.08$. All subjects underwent colonoscopy for surveillance; of these, $682(63.2 \%)$ had previously undergone surveillance colonoscopy, and 293 (27.2\%) had a history of abdominal surgery (Table 1). Polyps were detected in $41.4 \%$ of the subjects and adenomatous polyps in $28.0 \%$.

Table 2 shows the characteristics of the optimal and the suboptimal bowel preparation groups. The percentage of subjects with BMI $>25 \mathrm{~kg} / \mathrm{m}^{2}$ was significantly higher in subjects with suboptimal bowel preparation than in subjects with optimal bowel preparation $(\mathrm{P}=0.005)$. In contrast, the mean waist-to-hip ratios were similar $(0.89 \pm 0.07$ vs. $0.89 \pm 0.08, P=0.365)$. Other variables, such as history of abdominal surgery, comorbidities (e.g., hypertension, diabetes, constipation), and social habits (e.g., alcohol use, smoking) did not differ significantly between these two groups. Mean red meat intake was significantly higher in subjects with suboptimal bowel preparation than in those with optimal bowel preparation $(73.73 \pm 76.62 \mathrm{~g} /$ day vs. $64.67 \pm 62.20 \mathrm{~g} /$ day, $\mathrm{P}$ $=0.042)$. Other dietary factors did not differ significantly between
Table 1. Demographic and clinical characteristics of the study population $(\mathrm{n}=1,079)$

\begin{tabular}{lc}
\hline Characteristic & Value \\
\hline Age $(\mathrm{yr})$ & $49.6 \pm 8.32$ \\
Male sex & $680(63.0)$ \\
Body mass index $\left(\mathrm{kg} / \mathrm{m}^{2}\right)$ & $24.0 \pm 2.9$ \\
Waist-to-hip ratio & $0.89 \pm 0.08$ \\
Experience of colonoscopy & $682(63.2)$ \\
History of abdominal surgery & $293(27.2)$ \\
Cecal intubation time (min) & $6.95 \pm 4.69$ \\
Polyp detection rate & $446(41.3)$ \\
Adenoma detection rate & $302(28.0)$ \\
\hline
\end{tabular}

Values are presented as mean \pm standard deviation or number (\%).

\section{these 2 groups.}

Table 3 shows the association between BMI and suboptimal bowel preparation. Subjects with higher BMI were at significantly higher risk for suboptimal bowel preparation. BMI $>30 \mathrm{~kg} / \mathrm{m}^{2}$ was significantly associated with suboptimal bowel preparation on both the univariate (OR, 3.20; 95\% CI, 0.92-11.15; $\mathrm{P}=0.041$ ) and the multivariate $(\mathrm{OR}, 3.75$; $95 \% \mathrm{CI}, 1.00-14.16 ; \mathrm{P}=0.042)$ logistic regression analyses. In contrast, no factor associated with the level of nutrition of food intake was significantly associated with adequacy of bowel preparation on either the univariate or the multivariate logistic regression analyses (Table 4).

\section{DISCUSSION}

This study found that obesity was an independent risk factor for suboptimal bowel preparation quality in subjects undergoing surveillance colonoscopy. Although dietary factors associated with bowel preparation were also analyzed because we expected suboptimal bowel preparation to be associated with ingestion of a higher amount of dietary fiber, we found no association between dietary patterns and the adequacy of bowel preparation.

In Korea, traditional diets contain higher amounts of fiber and rice and lower amounts of red meat than Western diets. Industrialization, however, has caused Korean diets to become more westernized. Nevertheless, vegetable intake remains higher in Korean than in Western diets. We hypothesized that dietary patterns and lifestyle factors would have an impact on bowel preparation. However, we found that dietary patterns and lifestyle factors were not associated with the quality of bowel preparation.

Factors shown to be important in the quality of bowel preparation include dietary restrictions and timing of colonoscopy [1517]. For example, a low residue diet for 2 days before colonoscopy was found to improve the quality of bowel preparation [18], suggesting that a low residue diet before colonoscopy is essential for optimizing the quality of bowel preparation. However, a clear liq- 


\section{Coloproctology Jong Hee Hyun, et al.}

Table 2. Characteristics of subjects with optimal and suboptimal preparation quality

\begin{tabular}{|c|c|c|c|c|}
\hline Variable & All subjects $(n=1,079)$ & Optimal preparation $(n=657)$ & Suboptimal preparation $(n=422)$ & P-value \\
\hline Age (yr) & $49.6 \pm 8.3$ & $53.0 \pm 8.4$ & $54.1 \pm 21.7$ & 0.347 \\
\hline \multicolumn{5}{|l|}{ Sex } \\
\hline Male & $680(63.0)$ & $419(63.8)$ & $261(61.8)$ & 0.561 \\
\hline Female & $399(37.0)$ & $238(36.2)$ & $161(38.2)$ & \\
\hline Body mass index $\left(\mathrm{kg} / \mathrm{m}^{2}\right)$ & $24.0 \pm 2.9$ & $23.9 \pm 2.8$ & $24.3 \pm 3.0$ & 0.030 \\
\hline$\leq 25$ & $707(65.5)$ & $452(68.8)$ & $255(60.4)$ & 0.005 \\
\hline$>25$ & $372(34.5)$ & $205(31.2)$ & $167(39.6)$ & \\
\hline Waist circumference & $85.4 \pm 8.4$ & $85.3 \pm 8.3$ & $85.5 \pm 8.6$ & 0.700 \\
\hline$<90 \mathrm{~cm}$ for males, $<80 \mathrm{~cm}$ for females & $574(53.2)$ & $358(54.5)$ & $216(51.2)$ & 0.317 \\
\hline$\geq 90 \mathrm{~cm}$ for males, $\geq 80 \mathrm{~cm}$ for females & $503(46.6)$ & $298(45.4)$ & $205(48.6)$ & \\
\hline Missing & $2(0.2)$ & $1(0.1)$ & $1(0.2)$ & \\
\hline Waste-to-hip ratio & $0.89 \pm 0.08$ & $0.89 \pm 0.07$ & $0.89 \pm 0.08$ & 0.365 \\
\hline \multicolumn{5}{|l|}{ Colonoscopy Hx } \\
\hline Yes & $682(63.2)$ & $411(62.6)$ & $271(64.2)$ & 0.668 \\
\hline No & $321(29.7)$ & $198(30.1)$ & $123(29.2)$ & \\
\hline Missing & $76(7.1)$ & $48(7.3)$ & $28(6.6)$ & \\
\hline \multicolumn{5}{|l|}{ Abdominal surgery } \\
\hline Yes & $293(27.2)$ & $181(27.6)$ & $112(26.5)$ & 0.779 \\
\hline No & $684(63.4)$ & $416(63.3)$ & 268 (63.5) & \\
\hline Missing & $102(9.4)$ & $60(9.1)$ & $42(10.0)$ & \\
\hline \multicolumn{5}{|l|}{ Hypertension } \\
\hline Present & $212(19.6)$ & 128 (19.5) & 84 (19.9) & 0.865 \\
\hline Absent & $867(80.4)$ & $529(80.5)$ & $338(80.1)$ & \\
\hline \multicolumn{5}{|l|}{ Diabetes } \\
\hline Present & $71(6.6)$ & $38(5.8)$ & $33(7.8)$ & 0.188 \\
\hline Absent & $1,008(93.4)$ & 619 (94.2) & 389 (92.2) & \\
\hline \multicolumn{5}{|l|}{ Constipation } \\
\hline Present & $91(8.4)$ & $55(8.4)$ & $36(8.5)$ & 0.841 \\
\hline Absent & $701(65.0)$ & $416(63.3)$ & $285(67.5)$ & \\
\hline Missing & 287 (26.6) & $186(28.3)$ & $101(24.0)$ & \\
\hline \multicolumn{5}{|l|}{ Education level } \\
\hline High school or less & $446(41.3)$ & 266 (40.5) & $180(42.7)$ & 0.460 \\
\hline College or more & $588(54.5)$ & $364(55.4)$ & $224(53.1)$ & \\
\hline Missing & $45(4.2)$ & $27(4.1)$ & $18(4.2)$ & \\
\hline \multicolumn{5}{|l|}{ Regular exercise } \\
\hline No & $481(44.6)$ & $302(46.0)$ & $179(42.4)$ & 0.197 \\
\hline Yes & $316(29.3)$ & $184(28.0)$ & $132(31.3)$ & \\
\hline Missing & $282(26.1)$ & $171(26.0)$ & $111(26.3)$ & \\
\hline \multicolumn{5}{|l|}{ Alcohol consumption } \\
\hline Nondrinker & $286(26.5)$ & $170(25.9)$ & $116(27.5)$ & 0.817 \\
\hline Former drinker & $64(5.9)$ & $40(6.1)$ & $24(5.7)$ & \\
\hline Current drinker & $718(66.5)$ & $441(67.1)$ & 277 (65.6) & \\
\hline Missing & $11(1.1)$ & $6(0.9)$ & $5(1.2)$ & \\
\hline
\end{tabular}


Table 2. Continued

\begin{tabular}{|c|c|c|c|c|}
\hline Variable & All subjects $(n=1,079)$ & Optimal preparation $(n=657)$ & Suboptimal preparation $(n=422)$ & P-value \\
\hline \multicolumn{5}{|l|}{ Smoking status } \\
\hline Nonsmoker & $455(42.2)$ & $282(42.9)$ & $173(41.0)$ & 0.804 \\
\hline Former smoker & $330(30.6)$ & $199(30.3)$ & $131(31.0)$ & \\
\hline Current smoker & $278(25.8)$ & $166(25.3)$ & $112(26.5)$ & \\
\hline Missing & $16(1.4)$ & $10(1.5)$ & $6(1.5)$ & \\
\hline Energy intake (kcal/day) & $1,836.58 \pm 510.26$ & $1,820.15 \pm 483.51$ & $1,862.17 \pm 548.94$ & 0.199 \\
\hline Fiber (g/day) & $20.22 \pm 7.34$ & $20.27 \pm 7.48$ & $20.14 \pm 7.11$ & 0.790 \\
\hline Red meat (g/day) & $68.21 \pm 68.31$ & $64.67 \pm 62.20$ & $73.73 \pm 76.62$ & 0.042 \\
\hline Vegetable \& Fruit (g/day) & $526.84 \pm 272.43$ & $533.47 \pm 269.77$ & $516.52 \pm 276.54$ & 0.319 \\
\hline Carbohydrate (g/day) & $279.53 \pm 79.23$ & $279.82 \pm 77.84$ & $279.09 \pm 81.45$ & 0.883 \\
\hline Protein (g/day) & $71.31 \pm 22.82$ & $71.16 \pm 22.58$ & $71.56 \pm 23.21$ & 0.778 \\
\hline Fat (g/day) & $42.50 \pm 19.42$ & $41.54 \pm 18.33$ & $44.00 \pm 20.93$ & 0.049 \\
\hline Calcium (mg/day) & $498.82 \pm 216.25$ & $500.45 \pm 227.38$ & $496.28 \pm 197.92$ & 0.750 \\
\hline Cholesterol (mg/day) & $300.80 \pm 179.76$ & $301.40 \pm 175.30$ & $299.88 \pm 186.69$ & 0.893 \\
\hline Sodium (mg/day) & $4,273.66 \pm 1,805.84$ & $4,328.07 \pm 1,785.62$ & $4,188.95 \pm 1,835.79$ & 0.217 \\
\hline Folic acid ( $\mu \mathrm{g} /$ day) & $521.11 \pm 190.90$ & $520.62 \pm 194.22$ & $521.86 \pm 185.83$ & 0.917 \\
\hline
\end{tabular}

Values are presented as number (\%) or mean \pm standard deviation.

${ }^{a}$ BMl criteria are based on $\leq 25 \mathrm{~kg} / \mathrm{m}^{2}$ : normal, $>25 \mathrm{~kg} / \mathrm{m}^{2}$ : overweight + obesity.

Table 3. Association between body mass index and suboptimal bowel preparation

\begin{tabular}{lcll}
\hline Variable & $\begin{array}{c}\text { No. of optimal/ } \\
\text { suboptimal }\end{array}$ & \multicolumn{1}{c}{$\begin{array}{c}\text { Crude OR } \\
(95 \% \mathrm{Cl})\end{array}$} & $\begin{array}{c}\text { Multivariate OR } \\
(95 \% \mathrm{Cl})\end{array}$ \\
\hline $\begin{array}{l}\text { BMl }\left(\mathrm{kg} / \mathrm{m}^{2}\right)^{\mathrm{a}, \mathrm{b}} \\
\leq 25\end{array}$ & $452 / 255$ & 1.00 & 1.00 \\
$>25$ & $205 / 167$ & $1.44(1.12-1.86)$ & $1.42(1.11-1.85)$ \\
P-value & & 0.005 & 0.007 \\
BMl (kg/m²) & & & \\
$\leq 18.5$ & $16 / 5$ & 1.00 & 1.00 \\
$18.5-24.9$ & $428 / 248$ & $1.85(0.67-5.12)$ & $2.18(0.72-6.65)$ \\
$25.0-29.9$ & $199 / 155$ & $2.49(0.89-6.95)$ & $2.89(0.94-8.90)$ \\
$\geq 30$ & $14 / 14$ & $3.20(0.92-11.15)$ & $3.75(1.00-14.16)$ \\
P-value & & 0.041 & 0.042 \\
\hline
\end{tabular}

$\mathrm{BMl}$, body mass index; OR, odds ratio; $\mathrm{Cl}$, confidential interval.

${ }^{a}$ Adjusted for age, sex, smoking status, and alcohol consumption. ${ }^{\mathrm{B} B M l}$ criteria are based on (1) $\leq 25 \mathrm{~kg} / \mathrm{m}^{2}$ : normal, $>25 \mathrm{~kg} / \mathrm{m}^{2}$ : overweight + obesity. 'World Health Organization expert consultation, Lancet 2004;363(9403):157-63 [13].

uid diet was not mandatory for bowel preparation $[19,20]$.

The dietary survey in this study included questions about usual dietary patterns, not those 2 or 3 days before colonoscopy. We found no association between subjects' usual dietary patterns and the quality of bowel preparation. However, dietary patterns for several days immediately before colonoscopy were found to be important for optimizing the quality of bowel preparation.

Our results are consistent with those of previous studies, showing that obesity was a risk factor for suboptimal preparation quality. For example, 2 studies reported that BMI $\geq 30 \mathrm{~kg} / \mathrm{m}^{2}$ was an independent predictors of inadequate bowel preparation at colonoscopy (OR, 1.35; 95\% CI, 1.09-1.68; P = 0.006) [9, 21]. However, the reason for the association between obesity and suboptimal bowel preparation is not clear. Adequate bowel preparation has been found to be particularly important in obese subjects due to their increased incidence of colonic adenomas [22, 23]. Thus, suboptimal preparation in obese subjects may result in a higher rate of missed adenomas than in subjects whose $B M I \leq 25 \mathrm{~kg} / \mathrm{m}^{2}$. A more intensive preparation regimen may therefore benefit subjects with higher BMI. Preparation quality in obese subjects may be improved by a higher dose of current preparation regimens, the addition of another cathartic, a longer period of dietary restriction (low-residue diet and clear-liquid diet), and education to optimize understanding and compliance.

Inadequate bowel preparation has also been associated with delayed colonoscopy starting time; failure to follow preparation instructions; inpatient status; procedural indications of constipation, use of tricyclic antidepressants, male sex, a history of cirrhosis, stroke, or dementia, and a history of abdominal surgery, such as, an appendectomy, colorectal resection, or hysterectomy [24, 25]. This study found that other factors tested, including a history of abdominal surgery, older age, history of underlying disease, and usual dietary pattern, were not associated with quality of bowel 
Annals of Lifestyle Factors and Bowel Preparation for Screening Colonoscopy

\section{Coloproctology Jong Hee Hyun, et al.}

Table 4. Association between the level of nutrition and food intake and suboptimal bowel preparation

\begin{tabular}{|c|c|c|c|c|}
\hline Variable & Optimal $(n=657)$ & Suboptimal $(n=422)$ & Crude OR (95\% Cl) & Multivariate $\mathrm{OR}^{\mathrm{a}}(95 \% \mathrm{Cl})$ \\
\hline \multicolumn{5}{|c|}{ Energy intake (kcal/day) } \\
\hline$<1,461$ & 159 & 105 & 1.00 & 1.00 \\
\hline $1,461-1,800$ & 178 & 97 & $0.83(0.58-1.17)$ & $0.85(0.60-1.22)$ \\
\hline $1,800-2,129$ & 160 & 109 & $1.03(0.73-1.46)$ & $1.10(0.76-1.58)$ \\
\hline$>2,129$ & 160 & 111 & $1.05(0.74-1.48)$ & $1.13(0.78-1.65)$ \\
\hline P for trend ${ }^{b}$ & & & 0.491 & 0.299 \\
\hline \multicolumn{5}{|l|}{ Fiber (g/day) } \\
\hline$<15$ & 188 & 119 & 1.00 & 1.00 \\
\hline $15-19$ & 119 & 68 & $0.90(0.62-1.32)$ & $0.91(0.62-1.32)$ \\
\hline $19-24$ & 160 & 108 & $1.07(0.76-1.49)$ & $1.08(0.77-1.52)$ \\
\hline$>24$ & 190 & 127 & $1.06(0.77-1.46)$ & $1.09(0.78-1.52)$ \\
\hline P for trend & & & 0.591 & 0.496 \\
\hline \multicolumn{5}{|l|}{ Red meat (g/day) } \\
\hline$<18$ & 162 & 109 & 1.00 & 1.00 \\
\hline $18-48$ & 173 & 91 & $0.78(0.55-1.11)$ & $0.78(0.55-1.12)$ \\
\hline $48-102$ & 170 & 103 & $0.90(0.64-1.27)$ & $0.92(0.65-1.30)$ \\
\hline$>102$ & 152 & 119 & $1.16(0.83-1.64)$ & $1.20(0.84-1.71)$ \\
\hline P for trend & & & 0.138 & 0.110 \\
\hline \multicolumn{5}{|c|}{ Vegetable \& Fruit (g/day) } \\
\hline$<333$ & 155 & 115 & 1.00 & 1.00 \\
\hline $333-480$ & 169 & 100 & $0.80(0.57-1.13)$ & $0.79(0.56-1.12)$ \\
\hline 480-675 & 170 & 100 & $0.79(0.56-1.12)$ & $0.79(0.56-1.13)$ \\
\hline$>675$ & 163 & 107 & $0.89(0.63-1.25)$ & $0.89(0.62-1.27)$ \\
\hline P for trend & & & 0.618 & 0.681 \\
\hline \multicolumn{5}{|c|}{ Carbohydrate (g/day) } \\
\hline$<224$ & 157 & 113 & 1.00 & 1.00 \\
\hline 224-272 & 176 & 92 & $0.73(0.51-1.03)$ & $0.74(0.52-1.06)$ \\
\hline $272-330$ & 162 & 105 & $0.90(0.64-1.27)$ & $0.93(0.65-1.33)$ \\
\hline$>330$ & 162 & 112 & $0.96(0.68-1.35)$ & $1.01(0.70-1.44)$ \\
\hline P for trend & & & 0.820 & 0.624 \\
\hline \multicolumn{5}{|l|}{ Protein (g/day) } \\
\hline$<55$ & 162 & 113 & 1.00 & 1.00 \\
\hline $55-68$ & 155 & 93 & $0.86(0.61-1.22)$ & $0.90(0.63-1.29)$ \\
\hline $68-84$ & 170 & 110 & $0.93(0.66-1.30)$ & $0.94(0.66-1.33)$ \\
\hline$>84$ & 170 & 106 & $0.89(0.64-1.26)$ & $0.93(0.65-1.33)$ \\
\hline P for trend & & & 0.629 & 0.756 \\
\hline \multicolumn{5}{|l|}{ Fat (g/day) } \\
\hline$<28$ & 175 & 97 & 1.00 & 1.00 \\
\hline $28-39$ & 147 & 101 & $1.24(0.87-1.77)$ & $1.25(0.87-1.78)$ \\
\hline $39-53$ & 180 & 107 & $1.07(0.76-1.51)$ & $1.07(0.76-1.53)$ \\
\hline$>53$ & 155 & 117 & $1.36(0.96-1.92)$ & $1.41(0.98-2.01)$ \\
\hline P for trend & & & 0.134 & 0.102 \\
\hline
\end{tabular}

(Continued to the next page) 
Table 4. Continued

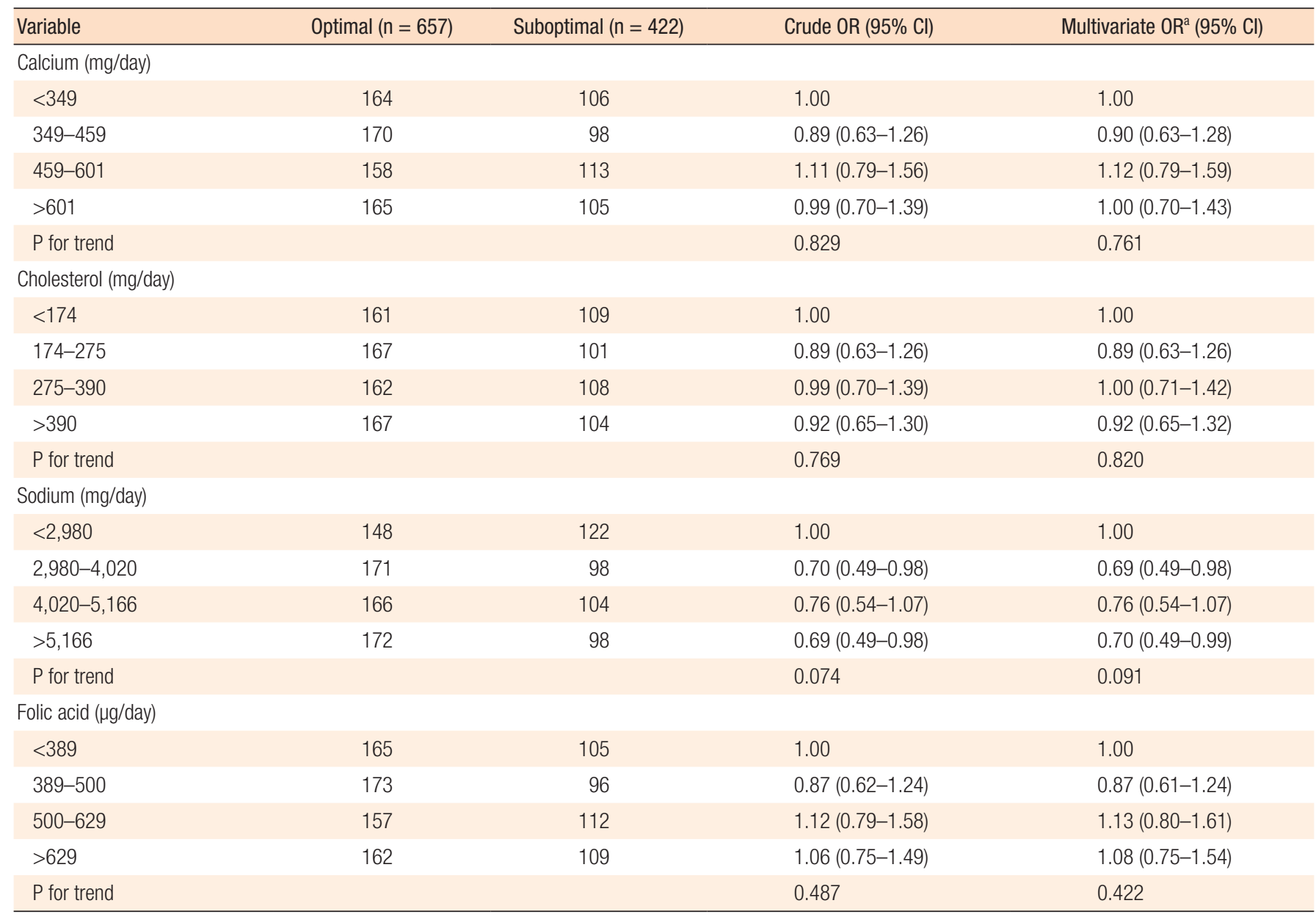

$\mathrm{OR}$, odds ratio; $\mathrm{Cl}$, confidential interval.

adjusted for age, sex, smoking status and alcohol consumption. ${ }^{\mathrm{b}}$ Test for trend calculated with median intake of each category of intake as a continuous variable.

preparation.

Subjects in this study population underwent colonoscopy as part of their personal health checkups and paid its costs personally, suggesting that these subjects were more interested in healthcare and more likely to pay attention to bowel preparation than other subjects. Surprisingly, however, the overall rate of suboptimal bowel preparation was higher in this study than in previous studies. Recent results, and the guideline of the European Society of Gastrointestinal Endoscopy recommend a split-dose regimen for bowel preparation, with time between the last dose of preparation and colonoscopy being no longer than four hours [26]. This protocol was difficult to apply to our study population, as these subjects underwent colonoscopy early in the morning. Moreover, many individuals underwent colonoscopy more than four hours after bowel preparation because they also underwent abdominal ultrasound and/or esophagogastroduodenoscopy on the same day. This is very common in Korea and Japan, where the incidence rates of stomach and liver cancer are higher than in West- ern countries.

Our study had several limitations, including its retrospective design. However, the data were collected prospectively. Another limitation was its performance at a single institution, the Center for Cancer Prevention and Detection of the National Cancer Center in Korea, which may limit generalization of its results to other populations. Moreover, the determination of preparation quality can vary significantly among endoscopists. The average scores of bowel preparation quality were assessed in each segment of the colon by using the Aronchick scale and were not routinely documented based on evaluation before and after lavage. Thus, the assessment of bowel preparation quality likely showed high interobserver variability.

In conclusion, this study found that lifestyle factors, especially dietary patterns, were not associated with the quality of bowel preparation whereas obesity was associated with suboptimal bowel preparation. A more intensive preparation regimen and more intensive dietary restrictions before colonoscopy may result 
in better bowel preparation in subjects with a BMI $\geq 25 \mathrm{~kg} / \mathrm{m}^{2}$.

\section{CONFLICT OF INTEREST}

No potential conflict of interest relevant to this article was reported.

\section{ACKNOWLEDGMENTS}

This work was supported by a National Cancer Center Grant (NCC-1410250 \& NCC-1510150).

\section{REFERENCES}

1. Jung KW, Won YJ, Kong HJ, Oh CM, Cho H, Lee DH, et al. Cancer statistics in Korea: incidence, mortality, survival, and prevalence in 2012. Cancer Res Treat 2015;47:127-41.

2. Winawer SJ, Zauber AG, Ho MN, O’Brien MJ, Gottlieb LS, Sternberg SS, et al. Prevention of colorectal cancer by colonoscopic polypectomy. The National Polyp Study Workgroup. N Engl J Med 1993;329:1977-81.

3. Kaminski MF, Regula J, Kraszewska E, Polkowski M, Wojciechowska U, Didkowska J, et al. Quality indicators for colonoscopy and the risk of interval cancer. N Engl J Med 2010;362:1795-803.

4. Pohl J, Halphen M, Kloess HR, Fischbach W. Impact of the quality of bowel cleansing on the efficacy of colonic cancer screening: a prospective, randomized, blinded study. PLoS One 2015;10: e0126067.

5. Harewood GC, Sharma VK, de Garmo P. Impact of colonoscopy preparation quality on detection of suspected colonic neoplasia. Gastrointest Endosc 2003;58:76-9.

6. Froehlich F, Wietlisbach V, Gonvers JJ, Burnand B, Vader JP. Impact of colonic cleansing on quality and diagnostic yield of colonoscopy: the European Panel of Appropriateness of Gastrointestinal Endoscopy European multicenter study. Gastrointest Endosc 2005;61:378-84.

7. Rex DK, Bond JH, Winawer S, Levin TR, Burt RW, Johnson DA, et al. Multi-Society Task Force on Colorectal Cancer. Quality in the technical performance of colonoscopy and the continuous quality improvement process for colonoscopy: recommendations of the U.S. Multi-Society Task Force on Colorectal Cancer. Am J Gastroenterol 2002;97:1296-308.

8. Lebwohl B, Kastrinos F, Glick M, Rosenbaum AJ, Wang T, Neugut AI. The impact of suboptimal bowel preparation on adenoma miss rates and the factors associated with early repeat colonoscopy. Gastrointest Endosc 2011;73:1207-14.

9. Fayad NF, Kahi CJ, Abd El-Jawad KH, Shin AS, Shah S, Lane KA, et al. Association between body mass index and quality of split bowel preparation. Clin Gastroenterol Hepatol 2013;11:1478-85.

10. Cheng RW, Chiu YC, Wu KL, Rayner CK, Tai WC, Hu ML, et al. Predictive factors for inadequate colon preparation before colonoscopy. Tech Coloproctol 2015;19:111-5.
11. Stolpman DR, Solem CA, Eastlick D, Adlis S, Shaw MJ. A randomized controlled trial comparing a low-residue diet versus clear liquids for colonoscopy preparation: impact on tolerance, procedure time, and adenoma detection rate. J Clin Gastroenterol 2014;48:851-5.

12. Choi YS, Joung H, Moon HK. Revision of dietary reference intakes for Koreans in 2010. FASEB J. 2011;25(1 Suppl):993.

13. WHO Expert Consultation. Appropriate body-mass index for Asian populations and its implications for policy and intervention strategies. Lancet 2004;363:157-63.

14. Aronchick CA, Lipshutz WH, Wright SH, DuFrayne F, Bergman G. Validation of an instrument to assess colon cleansing [abstract]. Am J Gastroenterol 1999;94:2667.

15. El Sayed AM, Kanafani ZA, Mourad FH, Soweid AM, Barada KA, Adorian CS, et al. A randomized single-blind trial of whole versus split-dose polyethylene glycol-electrolyte solution for colonoscopy preparation. Gastrointest Endosc 2003;58:36-40.

16. Aoun E, Abdul-Baki H, Azar C, Mourad F, Barada K, Berro Z, et al. A randomized single-blind trial of split-dose PEG-electrolyte solution without dietary restriction compared with whole dose PEG-electrolyte solution with dietary restriction for colonoscopy preparation. Gastrointest Endosc 2005;62:213-8.

17. Church JM. Effectiveness of polyethylene glycol antegrade gut lavage bowel preparation for colonoscopy--timing is the key! Dis Colon Rectum 1998;41:1223-5.

18. Wu KL, Rayner CK, Chuah SK, Chiu KW, Lu CC, Chiu YC. Impact of low-residue diet on bowel preparation for colonoscopy. Dis Colon Rectum 2011;54:107-12.

19. Park DI, Park SH, Lee SK, Baek YH, Han DS, Eun CS, et al. Efficacy of prepackaged, low residual test meals with $4 \mathrm{~L}$ polyethylene glycol versus a clear liquid diet with $4 \mathrm{~L}$ polyethylene glycol bowel preparation: a randomized trial. J Gastroenterol Hepatol 2009;24: 988-91.

20. Jung YS, Seok HS, Park DI, Song CS, Kim SE, Lee SH, et al. A clear liquid diet is not mandatory for polyethylene glycol-based bowel preparation for afternoon colonoscopy in healthy outpatients. Gut Liver 2013;7:681-7.

21. Borg BB, Gupta NK, Zuckerman GR, Banerjee B, Gyawali CP. Impact of obesity on bowel preparation for colonoscopy. Clin Gastroenterol Hepatol 2009;7:670-5.

22. Ben Q, An W, Jiang Y, Zhan X, Du Y, Cai QC, et al. Body mass index increases risk for colorectal adenomas based on meta-analysis. Gastroenterology 2012;142:762-72.

23. Okabayashi K, Ashrafian H, Hasegawa H, Yoo JH, Patel VM, Harling $\mathrm{L}$, et al. Body mass index category as a risk factor for colorectal adenomas: a systematic review and meta-analysis. Am J Gastroenterol 2012;107:1175-85.

24. Ness RM, Manam R, Hoen H, Chalasani N. Predictors of inadequate bowel preparation for colonoscopy. Am J Gastroenterol 2001;96:1797-802.

25. Chung YW, Han DS, Park KH, Kim KO, Park CH, Hahn T, et al. Patient factors predictive of inadequate bowel preparation using 
polyethylene glycol: a prospective study in Korea. J Clin Gastroenterol 2009;43:448-52.

26. Hassan C, Bretthauer M, Kaminski MF, Polkowski M, Remback- en B, Saunders B, et al. Bowel preparation for colonoscopy: European Society of Gastrointestinal Endoscopy (ESGE) guideline. Endoscopy 2013;45:142-50. 